\title{
Molecular authentication of the medicinal herb Ruta graveolens (Rutaceae) and an adulterant using nuclear and chloroplast DNA markers
}

\author{
F. Al-Qurainy, S. Khan, M. Tarroum, F.M. Al-Hemaid and M.A. Ali \\ Department of Botany and Microbiology, College of Science, \\ King Saud University, Riyadh, Saudi Arabia
}

Corresponding author: S. Khan

E-mail: salimkhan17@yahoo.co.in

Genet. Mol. Res. 10 (4): 2806-2816 (2011)

Received May 9, 2011

Accepted September 12, 2011

Published November 10, 2011

DOI http://dx.doi.org/10.4238/2011.November.10.3

\begin{abstract}
Dried parts of different plant species often look alike, especially in powdered form, making them very difficult to identify. Ruta graveolens, sold as a dried medicinal herb, can be adulterated with Euphorbia dracunculoides. The genomic DNA was isolated from the leaf powder (100 mg each) using the modified CTAB method. Internal transcribed spacer sequences of nuclear ribosomal DNA (nrDNA-ITS), and chloroplast spacer sequences (rpoB and rpoCl) are regarded as potential genes for plant DNA barcoding. We amplified and sequenced these spacer sequences and confirmed the sequences with a BLAST search. Sequence alignment was performed using ClustalX to look for differences in the sequences. A DNA marker was developed based on rpoB and rpoCl of the nrDNA-ITS for the identification of the adulterant $E$. dracunculoides in samples of $R$. graveolens that are sold in local herbal markets. Sequence-characterized amplified region markers of 289 and $264 \mathrm{bp}$ for $R$. graveolens and $424 \mathrm{bp}$ for E. dracunculoides were developed from dissimilar sequences of this
\end{abstract}


nrDNA-ITS to speed up the authentication process. This marker successfully distinguished these species in extracted samples with as little as $5 \mathrm{ng} \mathrm{DNA} / \mu \mathrm{L}$ extract.

Key words: Chloroplast spacer sequences; SCAR marker; Herbal drugs; Euphorbia dracunculoides; nrDNA; Ruta graveolens

\section{INTRODUCTION}

The adulteration of medicinal plants from other plant species, which have similar morphology, is a common issue in herbal markets. The adulteration of these herbal drugs may be intentional or non-intentional at any stage of the plant materials. Therefore, authentication of raw medicinal plants is a fundamental requirement for quality assurance in herbal drug markets. Recently, efforts have been made to obtain accurate identification of medicinal plants used in raw drug trade to ensure the purity, quality and safety of the drugs (Jayasinghe et al., 2009). The morphological, biochemical or histological characteristics employed in the identification are less reproducible (Kiran et al., 2010) under different environmental conditions. Limitations of these markers for authentication of herbal drugs have generated a need to develop more reproducible molecular markers for quality control of these medicinal herbs. Similarly, phytochemical-based analysis methods, such as Fourier transform infrared spectroscopy, high-performance liquid chromatography mass spectrometry, nuclear magnetic resonance spectroscopy, and thin-layer chromatography, are generally used in the authentication of plant materials (Fugel et al., 2005; Kurtz et al., 2010). However, in some cases, phytochemical profiles may alter within the same species because of external factors such as temperature, light, humidity, soil composition and $\mathrm{pH}$, storage conditions, etc. Therefore, DNA-based authentication methods are reproducible for any fresh as well as dried old material where a great extent of confusion exists.

Internal transcribed spacer (ITS) sequences of nuclear ribosomal DNA (nrDNA) have been extensively used for phylogenetic study among plant species (Choo et al., 2009; Gulbitti-Onarici et al., 2009), molecular discrimination of herbal materials (Zhang et al., 2007) and DNA barcoding (Zuo et al., 2011). The nrDNA-ITS region has frequent insertions/ deletions, which can be phylogenetically informative (Baldwin et al., 1995). The conserved regions of ITS region including $18 \mathrm{~S}$ and $28 \mathrm{~S}$ genes of nuclear ribosomal transcriptional unit are used to infer phylogenetic relationships at higher taxonomic levels, whereas the more rapidly evolving segments (ITS and IGS) are used for studies at the genic or population levels (Alvarez and Wendel, 2003). Besides nrDNA-ITS sequences, there are other gene spacer sequences and non-coding region in the plant genome, which also have the priority of identification and authentication at inter-specific level and at inter-generic level of the plants. Chloroplast genes are a versatile tool for the plant identification and barcoding to establishing genetic relationship among various plant species (Nock et al., 2011). Chloroplast contains highly conserved genes, which are fundamental for plant life, and more variable regions, which are informative over a broad time scale.

Several plants of the Rutaceae family are being used as a traditional medicine worldwide. A scented medicinal plant named Ruta graveolens L. [('rue' or 'sudab' in Hindi (India)], native to Europe is distributed throughout the world. This species has a 
more or less similarity to Euphorbia dracunculoides in fresh as well as in a dried state. The leaves are small, oblong, deeply divided, pinnate and glandular dotted with an unpleasant odor. The flower has four petals except for the central flower, which has five petals. The fruits are round, brown, small, and lobulated. The taste is slightly stinging but is masked by the strong bitter odor. E. dracunculoides Lam. (Euphorbiaceae) has a similar morphology to $R$. graveolens and is being sold as a substitute or adulterated with the above plant species (Khan et al., 2011; Al-Qurainy et al., 2011). The aqueous extract of $E$. dracunculoides has shown adverse effects such as epistaxis, nausea/vomiting and hematuria (Rahman et al., 2003), which were different from $R$. graveolens. The authentication of $R$. graveolens has been carried out in previous study with RAPD markers and ITS sequences of nrDNA (Khan et al., 2011; Al-Qurainy et al., 2011); however, due to less reproducibility of RAPD marker, it has generated a need to develop a more reproducible marker for the identification of this species in the herbal markets. Based on one marker, we cannot accurately authenticate the genuine as well as adulterant samples; therefore, a combined study should be performed for more precise authentication. Further, sequences from single chloroplast or nuclear genes have been useful for the identification and authentication of these plants, which have a similarity in morphological markers as well as in other markers. Therefore, we employed chloroplast spacer sequences ( $r p o B$ and rpoC1) and nrDNA-ITS for the authentication of $R$. graveolens and its adulterant $E$. dracunculoides. Since they have a number of valuable characteristics, i.e., the availability of conserved regions, there is an ease in their amplification, and sufficient variability to distinguish even closely related species. Furthermore, a sequence-characterized amplified region (SCAR) marker was developed for both genuine as well as adulterant samples from nrDNA-ITS sequence to avoid further sequencing stage, so that these plant species could easily be identified.

\section{MATERIAL AND METHODS}

\section{Sample collection from local herbal market}

Samples of $R$. graveolens were collected under the vernacular name 'sudab' from different shops of the local herbal market Khari Baoli, Delhi, India. All samples collected were identified by a taxonomist.

\section{Genomic DNA extraction and polymerase chain reaction (PCR) amplification}

The genomic DNA was isolated from the leaf powder (100 mg each) using the modified CTAB method (Khan et al., 2007). Total genomic DNA was employed in the PCR for the amplification of the ITS region of nrDNA, rpoB and rpoCl from $R$. graveolens (genuine) as well as $E$. dracunculoides (adulterant), respectively. The universal primers, sequence and their PCR conditions used in the amplification are given in Table 1.

The nrDNA-ITS was amplified from total genomic DNA according to the protocol by White et al. (1990) and Song et al. (2009). The PCR bead (GE Healthcare, UK) was employed for amplification and single reaction consisted of $20 \mu \mathrm{L}$ deionized sterile water, 25 ng DNA per reaction volume and $10 \mathrm{pm}$ of each forward and reverse primer. 


\begin{tabular}{llll}
\multicolumn{2}{l}{ Table 1. The universal gene specific primers, sequences and their reaction conditions. } \\
\hline Gene & Primer & Primer sequence $5^{\prime}-3^{\prime}$ & Reaction conditions \\
\hline nr ITS & Forward & GTCCACTGAACCTTATCATTTAG & $94^{\circ} \mathrm{C} 5 \mathrm{~min}$ \\
& Reverse & TCCTCCGCTTATTGATATGC & $94^{\circ} \mathrm{C} 1 \mathrm{~min}, 49^{\circ} \mathrm{C} 1 \mathrm{~min}, 40 \mathrm{cycles}$ \\
rpoB & Forward & ATGCAACGTCAAGCAGTTCC & $72^{\circ} \mathrm{C} 5 \mathrm{~min}$ \\
& Reverse & GATCCCAGCATCACAATTCC & $94^{\circ} \mathrm{C} 1 \mathrm{~min}$ \\
& Forward & $94^{\circ} \mathrm{C} 30 \mathrm{~s}, 53^{\circ} \mathrm{C} 40 \mathrm{~s}, 40 \mathrm{cycles}$ \\
rpoC1 & Reverse & GTGGATACACTTCTTGATAATGG & $72^{\circ} \mathrm{C} 5 \mathrm{~min}$ \\
& & CCATAAGCATATCTTGAGTTGG & $94^{\circ} \mathrm{C} 1 \mathrm{~min}$ \\
& & $94^{\circ} \mathrm{C} 30 \mathrm{~s}, 53^{\circ} \mathrm{C} 40 \mathrm{~s}, 40 \mathrm{cycles}$ \\
\hline
\end{tabular}

\section{PCR product purification and sequencing}

The amplified PCR products of the above genes were directly sequenced at Macrogen Inc., South Korea, using dye terminator chemistry. Cycle sequencing was conducted using the same primers used in amplification and BigDye version 3 reagents and an ABI PRISM 3100 DNA Analyzer (Perkin-Elmer, Applied Biosystems). Cycling conditions included an initial denaturing set at $94^{\circ} \mathrm{C}$ for $5 \mathrm{~min}$, followed by 30 cycles of $96^{\circ} \mathrm{C}$ for $10 \mathrm{~s}, 50^{\circ} \mathrm{C}$ for $5 \mathrm{~s}$, and $60^{\circ} \mathrm{C}$ for $4 \mathrm{~min}$. The sequencing product was precipitated with $17 \mu \mathrm{L}$ deionized sterile water, 3 $\mu \mathrm{L} 3 \mathrm{M}$ sodium acetate, and $70 \mu \mathrm{L} \mathrm{95 \%} \mathrm{ethanol.} \mathrm{Polyacrylamide} \mathrm{gel} \mathrm{electrophoresis} \mathrm{was} \mathrm{con-}$ ducted with long ranger single packs (FMC BioProducts) and an ABI 3100 automated DNA sequencer (Perkin-Elmer, Applied Biosystems). Each sample was sequenced in the sense and antisense direction and analyzed with the ABI Sequence Navigator software (Perkin-Elmer/ Applied Biosystems).

\section{Sequence analysis}

The sequence alignment was performed between genuine and adulterant samples to observe the sequence variations for their discrimination to each other. The ITS sequences of nrDNA, rpoB and rpoCl of $R$. graveolens and E. dracunculoides were obtained using the Basic Local Alignment Search Tool (BLAST) through http://blast.ncbi.nlm.nih.gov/Blast.cgi to confirm our sequence from related genus or species sequences available on NCBI database. All sequences generated from $R$. graveolens and E. dracunculoides in the present study had to be submitted to the GenBank ${ }^{\circledR}$. All three gene spacer sequences of both species were aligned using ClustalX version 1.81 (Thompson et al., 1997) to establish the degree of differences.

\section{Development of SCAR marker and its validation}

The nrDNA-ITS region has been used in phylogenetic analysis in the plants at generic and intra-generic levels. The length and sequences of nrDNA-ITS regions of ribosomal RNA repeats are believed to be quickly evolving and therefore may vary in the genome. Therefore, nrDNA-ITS region is believed to be a preferred choice for molecular typing of plant species. Moreover, in recent years, ITS sequence of nrDNA has been employed as genetic markers in various plant species (Zhang et al., 2007; Choo et al., 2009; Gulbitti-Onarici et al., 2009). These nrDNA-ITS fragments amplified from the genomic DNA samples of $R$. graveolens and $E$. dracunculoides were sequenced and sequence differences were observed through the 
Clustal-X software. For the development of SCAR marker, the species-specific primer was designed from dissimilar sequences of nrDNA-ITS using primer 3 tool. The higher dissimilarity of the sequence of nrDNA-ITS between genuine as well as adulterant samples has made development of SCAR marker successful. The sequence of the designed primers for the development of SCAR marker for $R$. graveolens and E. dracunculoids is shown in Table 2.

Table 2. SCAR primer sequences and their reaction conditions for the amplification of the SCAR marker.

\begin{tabular}{|c|c|c|c|c|}
\hline & Primer & Primer sequence 5'-3' & Product size (bp) & Reaction conditions \\
\hline SCAR289F & Forward & GATATCTCGGCTCTCGCATC & 289 & $94^{\circ} \mathrm{C} 5 \mathrm{~min}$ \\
\hline SCAR289R & Reverse & GCTTTGTTTTCACCACCGAT & & $\begin{array}{l}94^{\circ} \mathrm{C} 1 \mathrm{~min}, 48^{\circ} \mathrm{C} 45 \mathrm{~s}, 25 \text { cycles } \\
72^{\circ} \mathrm{C} 5 \mathrm{~min}\end{array}$ \\
\hline$S C A R 264 F$ & Forward & AGAACGTAGCGAAATGCGAT & 264 & $94^{\circ} \mathrm{C} 5 \mathrm{~min}$ \\
\hline$S C A R 264 R$ & Reverse & GCTTTGTTTTCACCACCGAT & & $\begin{array}{l}94^{\circ} \mathrm{C} 1 \mathrm{~min}, 48^{\circ} \mathrm{C} 45 \mathrm{~s}, 25 \text { cycles } \\
72^{\circ} \mathrm{C} 5 \mathrm{~min}\end{array}$ \\
\hline$S C A R 424 F$ & Forward & CGCAGCCTCATAACAAAACC & 424 & $94^{\circ} \mathrm{C} 5 \mathrm{~min}$ \\
\hline$S C A R 424 F$ & Reverse & AGCGAGGGTCTTACAACCAC & & $\begin{array}{l}94^{\circ} \mathrm{C} 1 \mathrm{~min}, 48^{\circ} \mathrm{C} 45 \mathrm{~s}, 25 \text { cycles } \\
72^{\circ} \mathrm{C} 5 \mathrm{~min}\end{array}$ \\
\hline
\end{tabular}

Furthermore, the marker was validated using the designed specific primer of one species with DNA of both samples in the PCR. The marker sensitivity was also checked using the serial dilution of DNA, which ranged from $5-25 \mathrm{ng} / 25 \mu \mathrm{L}$ reaction volume.

\section{RESULTS AND DISCUSSION}

DNA-based molecular tools are urgently needed to authenticate raw herbal materials in order to maintain their quality and efficacy in the herbal markets. These markers are more reproducible under wide variables as compared to other markers, whereas $R$. graveolens (sudab) has more similarities in morphological markers with $E$. dracunculoides and is easily adulterated and/or replaced in the local markets (Rahman et al., 2003; Khan et al., 2011). The bipinnate or tri-pinnate and obviate-oblong leaves of $R$. graveolens have more similarities with leaves of $E$. dracunculoides, which are lanceolate or linear oblong. R. graveolens has a strongsmell in dried as well as in fresh leaves, slightly toxic and a bitter in taste, whereas odor and taste are not distinct in the case of $E$. dracunculoides. The fruits of both species have extensive similarities and create more confusion, for example, $R$. graveolens has a capsule, 4-5 lobed globosely containing numerous seeds, tiny size, blackish and triangular in shape while $E$. $d r a-$ cunculoides also has capsule with subglobose shape, 3-celled, seeds ovoid-terete and gray or dark gray (Khan et al., 2011). R. graveolens was previously authenticated from its adulterant E. dracunculoides based on unique bands using RAPD markers (Khan et al., 2011). However, authentication of a medicinal herb should not depend on single marker, but it should be based on a combined study with the aim of producing a reproducible marker.

In the present study, three gene spacer sequences, viz, ITS sequence of nrDNA, rpoB and $r p o C l$, were used for the authentication of $R$. graveolens, which is being sold under the vernacular name 'sudab' in the Indian herbal markets. However, E. dracunculoides was found to be an adulterant when later very carefully identified at the species level at the National Institute of Science Communication and Information Resources (NISCAIR), New Delhi (voucher No. NISCAIR/RHMD/consult/-2007-08/937/121) (Khan et al., 2011). In the BLAST search, both samples showed a similarity with respective species or genus as nrDNA-ITS sequences 
with a genuine sample of 'sudab', i.e., $R$. graveolens showed $99 \%$ similarity to the $R$. graveolens (accession No. EU591989) available in the GenBank ${ }^{\circledR}$, whereas nrDNA-ITS sequences of adulterant sample showed $100 \%$ similarity with species of Euphorbia but did not show any similarity with genuine sample.

The chloroplast gene spacer sequences, viz, rpoB and rpoC1, amplified from $R$. graveolens showed a 96 and 99\% similarity with Citrus reticulata (rpoB2) (accession No. EF590436) and Ruta chalepensis chloroplast genome (accession No. EU531646) in the BLAST search, respectively. Similarly, rpoB and rpoC1 spacer sequences amplified from $E$. dracunculoides showed 95 and 98\% similarity with the Jatropha curcus (accession No. FJ695500) and Euphorbia lathyris (accession No. GQ435927), respectively. However, the phylogenetic relationship of E. dracunculoides together with Euphorbia species available in the GenBank ${ }^{\circledR}$ has clearly shown its complete nesting within the Euphorbia tree based on nrDNA-ITS sequences.

All gene spacer sequences were aligned and analyzed from comparable regions between genuine as well as adulterant samples. The insertions/deletion (indels) was counted between $R$. graveolens and $E$. dracunculoides sequences for their discrimination. The nrDNAITS region from 1-613 bases was found to show 199 indels (Figure 1). However, chloroplast gene spacer sequences rроB from 32-489 bases showed 55 insertions and $r p o C l$ region from 17-504 bases showed 47 insertions alone (Figures 2 and 3).

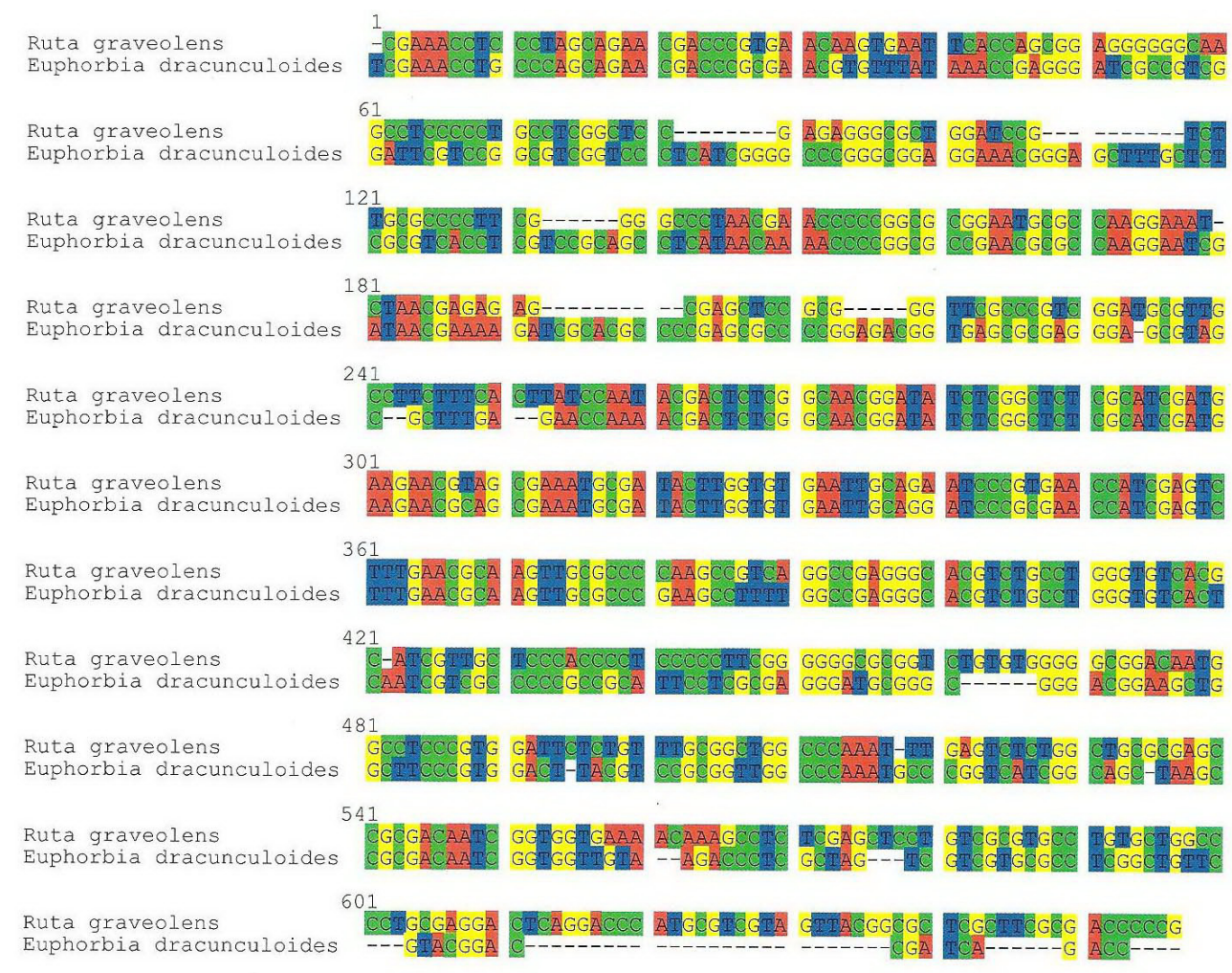

Figure 1. Complete alignment matrix of the internal transcribed spacer (ITS) gene sequences between Ruta graveolens and Euphorbia dracunculoides. 


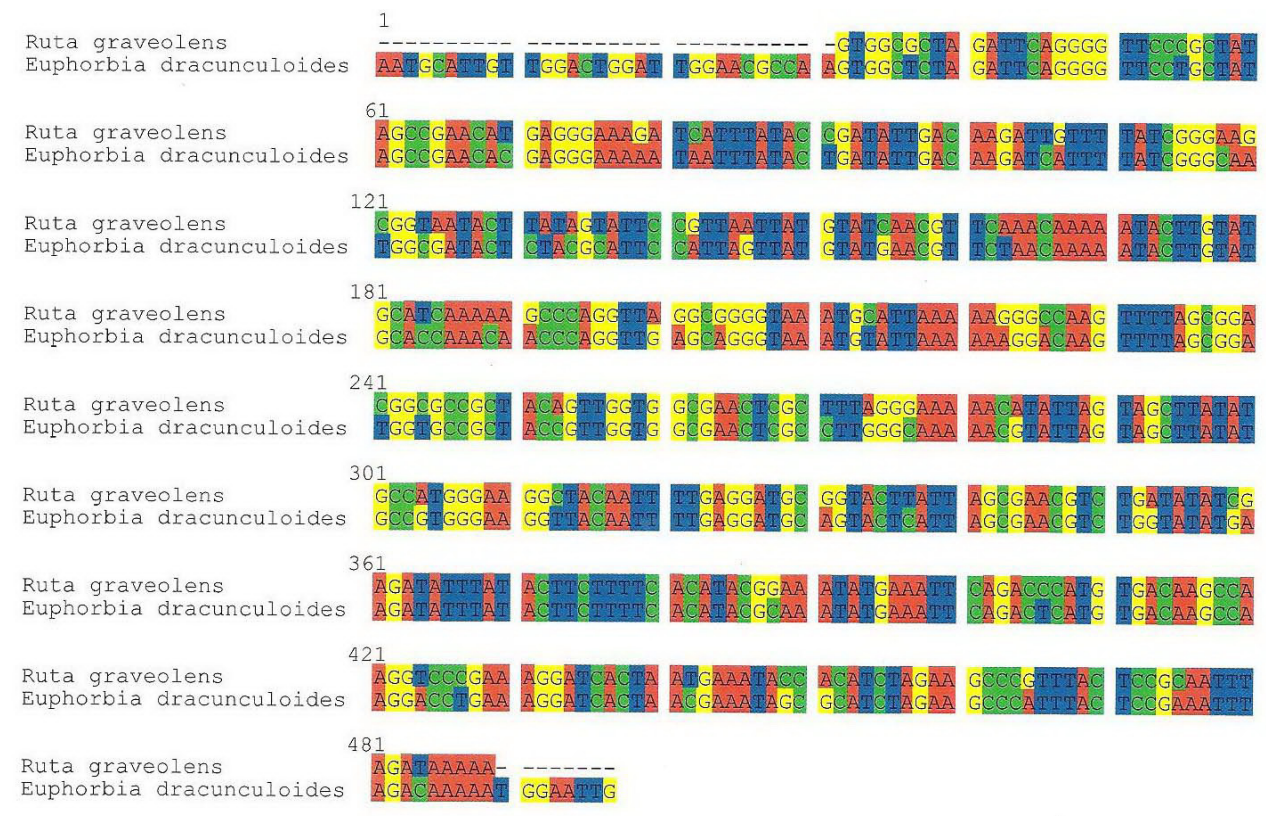

Figure 2. Complete alignment matrix of the chloroplast rpoB spacer sequence between Ruta graveolens and Euphorbia dracunculoides.

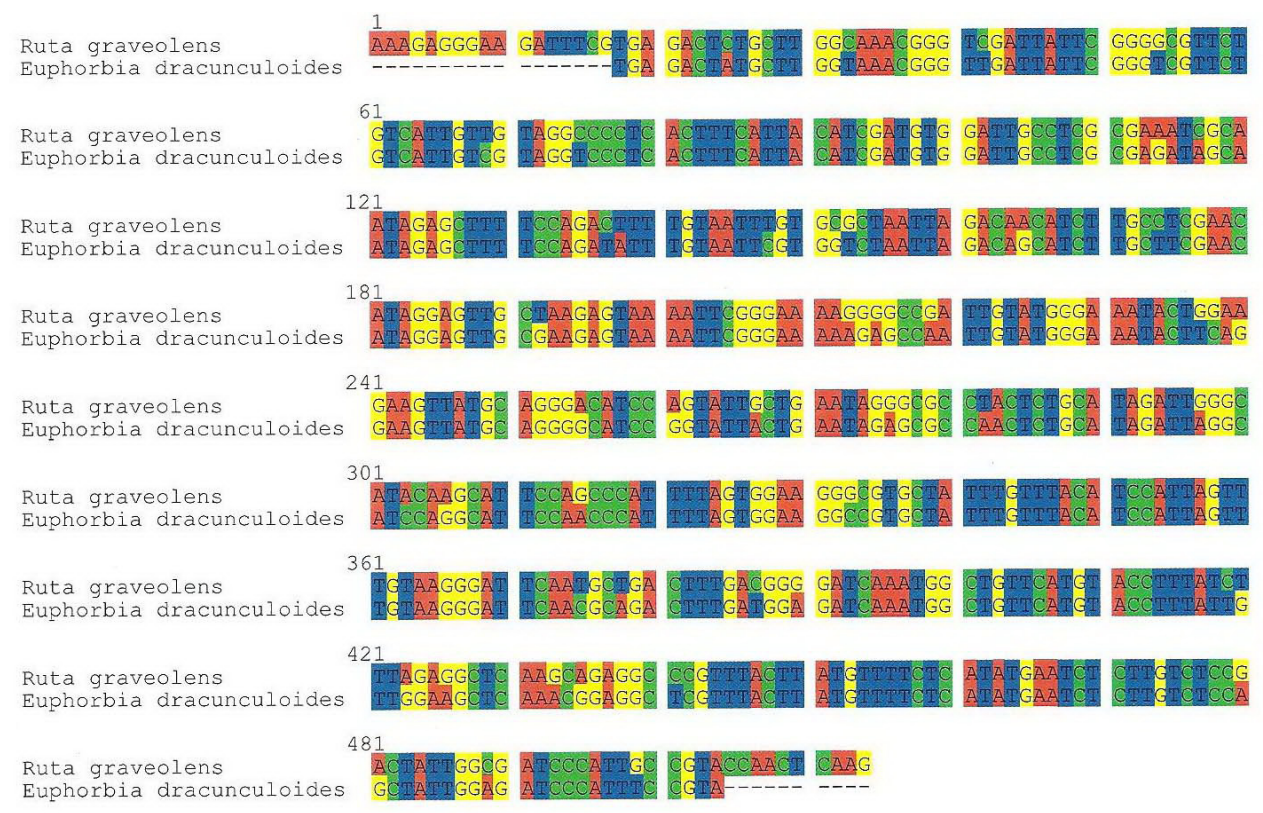

Figure 3. Complete alignment matrix of the chloroplast rpoC1 spacer sequence between Ruta graveolens and Euphorbia dracunculoides. 
There was no deleted base found in rpoB and rpoCl spacer sequences, whereas nrDNA-ITS sequences of both genuine and adulterant samples had insertions as well as deletions. Thus, molecular authentication based on these spacer sequences, i.e., ITS, rpoB and rpoCl, may represent the best markers to differentiate the genuine as well as adulterant samples of sudab. Thus, in future nrDNA-ITS and chloroplast spacer sequences could be utilized for the accurate identification of these species from commercial herbal products, which ultimately would ensure the reproducibility and the efficacy of genuine herbal drugs. Furthermore, nrDNA-ITS sequences showed more sequence variation as compared to chloroplast spacer sequences. Therefore, an SCAR marker was developed to speed up the authentication process and further avoid the sequencing stage whenever applied to these market samples. It is a monolocus dominant marker and uses specific primers, which was designed from dissimilar sequences of nrDNA-ITS. The development of this marker is easy, fast and reliable, less sensitive to reaction conditions, and easy to perform in any laboratory (Kethidi et al., 2003). Therefore, results are more reliable with this marker as compared to other markers. Similarly, the three species of orchid including Paphiopedilum armeniacum, P. micranthum and P. delenatii, native to southwestern China and Vietnam are endangered and currently listed as Convention on International Trade in Endangered Species of Wild Fauna and Flora (Liu et al., 2006). The SCAR marker was developed for these species from nrDNA-ITS sequences, which clearly differentiated them having a similar morphology (Sun et al., 2011). The designed SCAR primer from nrDNA-ITS sequences was employed with genomic DNA of both samples, which led to amplification of sizes (289 and $264 \mathrm{bp}$ ) for a genuine sample and $424 \mathrm{bp}$ for adulterant samples, respectively (Figure 4).

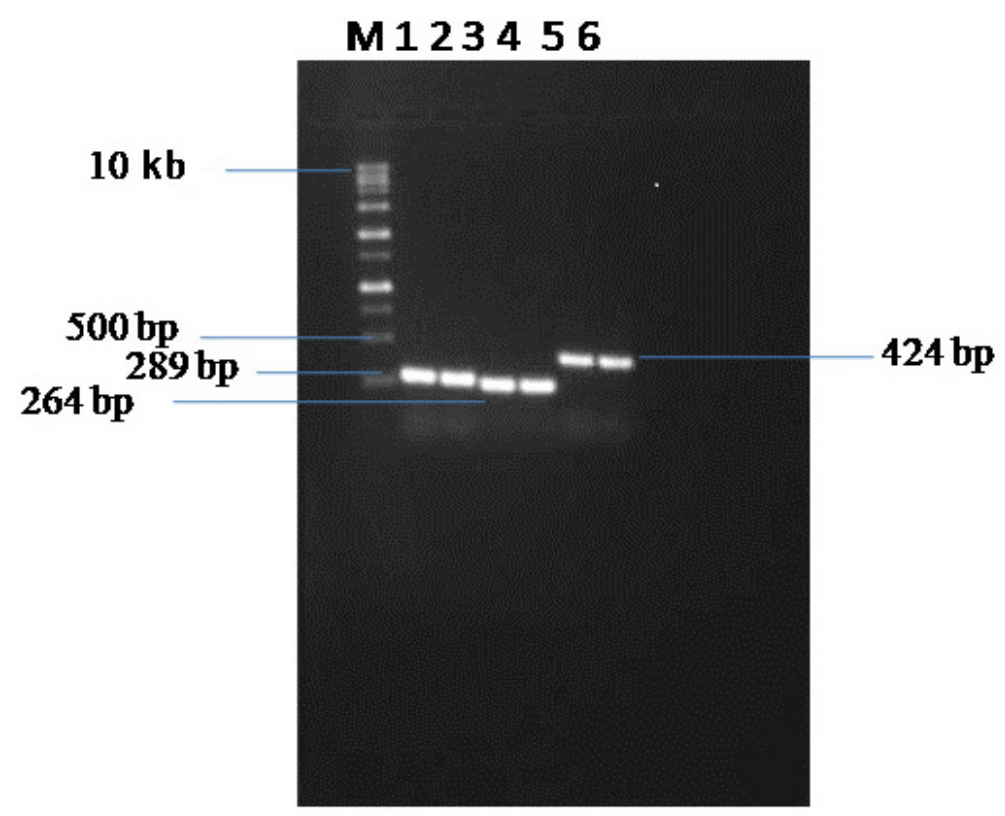

Figure 4. Sequence-characterized amplified region (SCAR) marker specific to Ruta graveolens amplified with SCAR289 (lanes 1 and 2) and SCAR264 primer (lanes 3 and 4). SCAR marker specific to Euphorbia dracunculoides amplified with SCAR424 primer (lanes 5 and 6 ). 
The sensitivity of developed SCAR marker was detected at different concentrations of genomic DNA, which ranged from 5-25 ng/25 $\mu \mathrm{L}$ PCR volume. As the concentration of genomic DNA decreased in the reaction mixture, the intensity of band also decreased (Figure $5 \mathrm{~A}, \mathrm{~B})$. This suggests that the DNA of above concentration, if present in the extracted genomic DNA of 'sudab', may have a limited amount of adulterant or totally replaced by adulterant samples. The developed SCAR marker will help in the authentication of these samples.

A

M12345678910

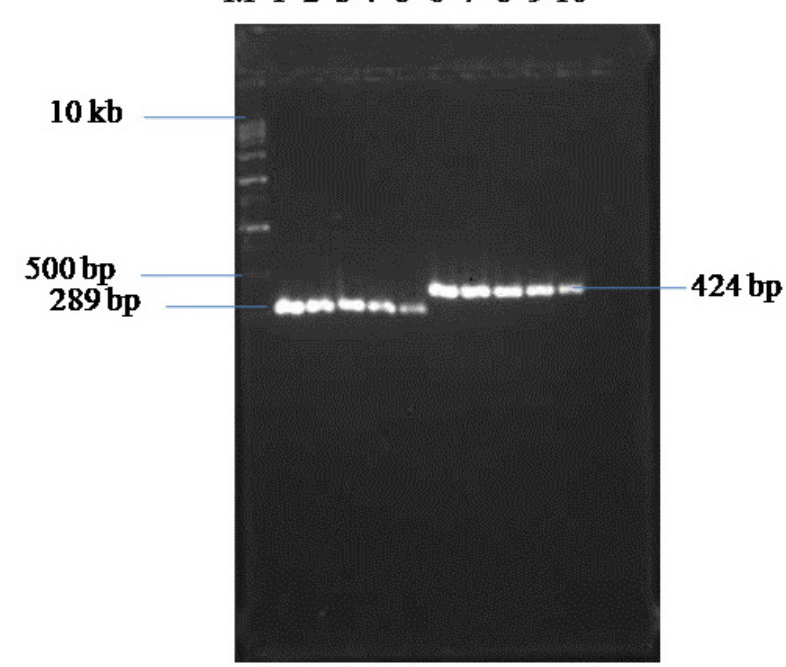

B

M 12345678910

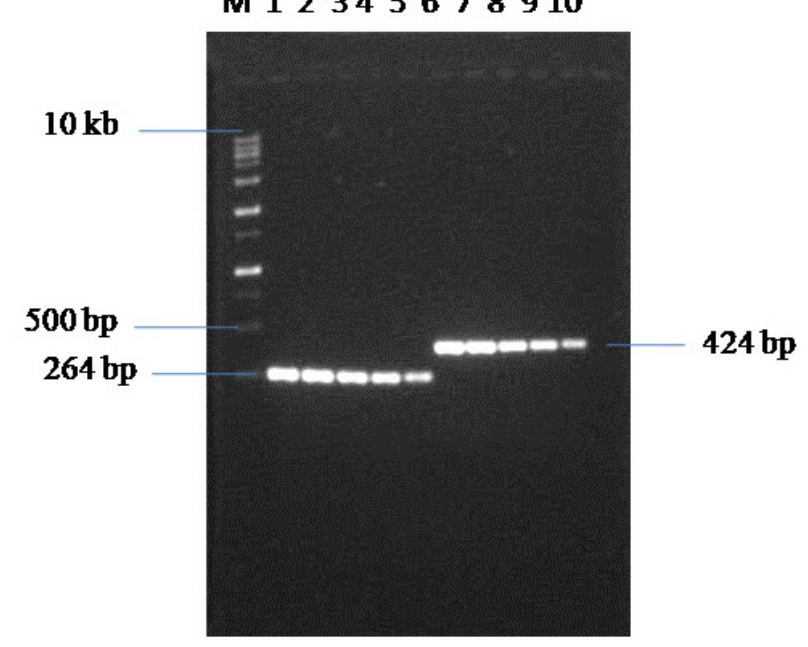

Figure 5. Detection of sequence-characterized amplified region (SCAR) marker sensitivity at various concentrations of genomic DNA. A. Amplification of genomic DNA of Ruta graveolens with SCAR289 Primer (lanes 1, 2, 3, 4, 5) and Euphorbia dracunculoides with SCAR 424 bp (lanes 6, 7, 8, 9, 10). B. Amplification of genomic DNA of R. graveolens with SCAR264 Primer (lanes 1, 2,3,4,5) and E. dracunculoides with SCAR 424 bp (lanes 6, 7, 8, 9, 10). 
Further, sequences of developed SCAR marker were BLAST on NCBI (http://www. ncbi.nlm.nih.gov/) and found exact respective plant species for which a marker was developed. The generated results in our study were considered to be reliable and have not been affected by physical form, physiological conditions of the plant samples and chemicals used in the study. However, compared with spacer sequences of chloroplast, the nrDNA-ITS region had more sequence variability. Therefore, ITS sequences of nrDNA show a wider prospect in authenticating the medicinal plants available in the herbal markets. The SCAR marker developed from nrDNA-ITS sequences has many advantages such as being easy to apply on dried old samples from which extracted genomic DNA may be sheared and/or obtained in small amounts. Nevertheless, DNA-based authentication of old and dried plant samples is a major challenge that is normally encountered in the raw drug trade. We isolated genomic DNA from dried powder form of genuine as well as adulterant samples and extracted genomic DNA was employed for PCR amplification (Khan et al., 2007). Once the SCAR marker is developed for such samples, which have high content of adulteration, it can be easily authenticated. Thus, the combined study of such DNA markers and further development of SCAR marker from dissimilar sequences of nrDNA-ITS can help in accurate authentication of 'sudab' sold in the market and can be applied on the other plant species, which have high morphological similarities.

\section{ACKNOWLEDGMENTS}

The authors extend their appreciation to the Deanship of Scientific Research at King Saud University for funding the study through the research group project \#RGP-VPP-014.

\section{REFERENCES}

Al-Qurainy F, Khan S, Ali MA, Al-Hemaid FM, et al. (2011). Authentication of Ruta graveolens and its adulterant using internal transcribed spacer (ITS) sequences of nuclear ribosomal DNA. Pak. J. Bot. 43: 1613-1620.

Alvarez I and Wendel JF (2003). Ribosomal ITS sequences and plant phylogenetic inference. Mol. Phylogenet. Evol. 29: 417-434.

Baldwin BG, Sanderson MJ, Porter JM, Wojciechowski MF, et al. (1995). The ITS region of nuclear ribosomal DNA: a valuable source of evidence on angiosperm phylogeny. Ann. Missouri Bot. Gard. 82: 247-277.

Choo BK, Moon BC, Yunui JI, Kim BB, et al. (2009). Development of SCAR markers for the discrimination of three species of medicinal plants, Angelica decursiva (Peucedanum decursivum) Peucedanum praeruptorum and Anthricus sylvestris, based on the internal transcribed spacer (ITS) sequence and random amplified polymorphic DNA (RAPD). Biol. Pharm. Bull. 32: 24-30.

Fugel R, Carle R and Schieber A (2005). Quality and authenticity control of fruit purées, fruit preparations and jams - a review. Trends Food Sci. Tech. 16: 433-441.

Gulbitti-Onarici S, Sancak C, Sumer S and Ozcan S (2009). Phylogenetic relationships of some wild wheat species based on the internal transcribed spacer sequences of nrDNA. Curr. Sci. 96: 794-800.

Jayasinghe R, Hai NL, Coram TE, Kong S, et al. (2009). Effectiveness of an innovative prototype subtracted diversity array (SDA) for fingerprinting plant species of medicinal importance. Planta Med. 75: 1180-1185.

Kethidi DR, Roden DB, Ladd TR, Krell PJ, et al. (2003). Development of SCAR markers for the DNA-based detection of the Asian long-horned beetle Anoplophora glabripennis (Motschulsky). Arch. Insect Biochem. Physiol. 52: 193-194.

Khan S, Qureshi MI, Kamaluddin, Tanweer A, et al. (2007). Protocol for isolation of genomic DNA from dry and fresh roots of medicinal plants suitable for RAPD and restriction digestion. Afr. J. Biotech. 6: 175-178.

Khan S, Mirza KJ, Tyagi MR and Abdin MZ (2011). Development of RAPD Markers for authentication of Ruta graveolens (L.) and its adulterant. MAPSB 5: 58-61.

Kiran U, Khan S, Mirza KJ, Ram M, et al. (2010). SCAR markers: a potential tool for authentication of herbal drugs. Fitoterapia 81: 969-976. 
Kurtz C, Leitenberger M, Carle R and Schieber A (2010). Evaluation of fruit authenticity and determination of the fruit content of fruit products using FTNIR spectroscopy of cell wall components. Food Chem. 119: 806-812.

Liu Z, Liu K, Chen L, Lei S, et al. (2006). Conservation ecology of endangered species Paphiopedilum armeniacum (Orchidaceae). Acta Ecol. Sin. 26: 2791-2800.

Nock CJ, Waters DL, Edwards MA, Bowen SG, et al. (2011). Chloroplast genome sequences from total DNA for plant identification. Plant Biotechnol. J. 9: 328-333.

Rahman SZ, Latif A and Singhal KC (2003). A case report of ADR due to misidentification of an indigenous drug. Indian J. Pharmacol. 35: 128-136.

Song J, Yao H, Li Y, Li X, et al. (2009). Authentication of the family polygonaceae in Chinese pharmacopoeia by DNA barcoding technique. J. Ethnopharmacol. 124: 434-439.

Sun YW, Yu JL, Hung YS, Changa JC, et al. (2011). Development of ITS sequence based SCAR markers for discrimination of Paphiopedilum armeniacum, Paphiopedilum micranthum, Paphiopedilum delenatii and their hybrids. Sci. Hortic. 127: 405-410.

Thompson JD, Gibson TJ, Plewniak F, Jeanmougin F, et al. (1997). The CLUSTAL_X windows interface: flexible strategies for multiple sequence alignment aided by quality analysis tools. Nucleic Acids Res. 25: 4876-4882.

White TJ, Bruns T, Lee S and Taylor J (1990). Amplification and Direct Sequencing of Fungal Ribosomal RNA Genes for Phylogenetics. In: PCR Protocols: A Guide to Methods and Applications (Innis M, Gelfand D, Sninsky J and White T, eds.). Academic Press, San Diego, 315-322.

Zhang YB, Shaw PC, Sze CW, Wang ZT, et al. (2007). Molecular authentication of Chinese herbal materials. J. Food Drug Anal. 15: 1-9.

Zuo Y, Chen Z, Kondo K, Funamoto T, et al. (2011). DNA barcoding of Panax species. Planta Med. 77: 182-187. 